\title{
Global Community of Disaster Risk Reduction Scientists and Decision Makers Endorse a Science and Technology Partnership to Support the Implementation of the Sendai Framework for Disaster Risk Reduction 2015-2030
}

\author{
Chloe Dickinson ${ }^{1}$ Amina Aitsi-Selmi ${ }^{1} \cdot$ Pedro Basabe $^{2} \cdot$ Chadia Wannous $^{2}$ • \\ Virginia Murray ${ }^{1,3}$
}

Published online: 25 March 2016

(C) The Author(s) 2016. This article is published with open access at Springerlink.com

At the first gathering of its kind on the role of science in implementing the Sendai Framework for Disaster Risk Reduction 2015-2030, over 750 scientists, policymakers, business people, and practitioners met in Geneva from January 27-29, 2016. The UNISDR Science and Technology Conference on the Implementation of the Sendai Framework for Disaster Risk Reduction 2015-2030 featured experts from some of the world's most disaster-prone countries. The conference brought together a diversity of science and technology community from all geographical regions, international partners and scientific disciplines, and a wide variety of other stakeholders including policymakers and nongovernmental organizations to discuss the barriers and opportunities to reducing disaster risk and loss in the coming 15 years. Attendees contributed to a lively and dynamic debate, including on social media using the hashtag \#science4sendai and reporting blogs from many of the organizations represented.

The Sendai Framework (UNISDR 2015a), agreed at the Third UN World Conference on Disaster Risk Reduction held in Sendai, Japan in March 2016, was adopted by the UN General Assembly on 3 June 2015. It places unprecedented emphasis on the role of science and technology in

Virginia Murray

virginia.murray@phe.gov.uk

Public Health England, London SE1 8UG, UK

2 United Nations Office for Disaster Risk Reduction, Geneva, Switzerland

3 Chair of the UNISDR Science and Technology Conference on the Implementation of the Sendai Framework for Disaster Risk Reduction 2015-2030, Vice-chair of the UNISDR Scientific and Technical Advisory Group (STAG),

URL: https://www.unisdr.org/ disaster risk reduction and calls for a strengthening of networks, platforms, and research institutions, a refocus on research into disaster risk patterns, and examining causes and effects. Its goal is to "prevent new and reduce existing disaster risk through the implementation of integrated and inclusive economic, structural, legal, social, health, cultural, educational, environmental, technological, political and institutional measures that prevent and reduce hazard exposure and vulnerability to disaster, increase preparedness for response and recovery, and thus strengthen resilience" (UNISDR 2015a, Paragraph 17).

The organizing committee of the conference, which included members of the UNISDR's Scientific and Technical Advisory Group (STAG), brought the wide range of stakeholders together to launch the UNISDR Science and Technology Partnership ${ }^{1}$ and the UNISDR Science and Technology Road Map to 2030 (UNISDR 2015b). The Road Map presents the expected outcomes under each of the four priorities for action outlined in the Sendai Framework, and proposes key actions that the UNISDR Science and Technology Partnership can undertake to fulfil the expected outcomes and to achieve the goal of the Sendai Framework. It also highlights ways for monitoring progress and reviewing needs. Both the Road Map and the Partnership were supported by the conference participants as promising ways forward to 2030 .

The conference discussions ${ }^{2}$ were arranged into four work streams that looked at opportunities to work

\footnotetext{
$\overline{1}$ The call for interest to join the Partnership was on the conference website and closed for applications currently at the end of February 2016: https://www.surveymonkey.com/r/3B6FCGG.

2 http://www.unisdr.org/partners/academia-research/conference/ $2016 /$.
} 
differently in order to address some of the real challenges in the Sendai Framework. These focused on:

(1) The way the Partnership would leverage local, national, regional, and international networks and platforms to advance multidisciplinary research and bring together science, policy, and practice;

(2) How disaster risk is understood, and how risks are assessed and early warning systems are designed;

(3) What data, standards, and innovative practices would be needed to measure and report on risk reduction; and

(4) What research and capacity gaps exist and how difficulties in creating and using science for effective disaster risk reduction can be overcome.

Under each work stream, three working groups were organized and debated in depth key areas of importance to advance the work of the Partnership and to feed into the Road Map.

Six side events were organized to highlight opportunities and address particular challenges in disaster risk reduction (DRR) or in DRR science. These comprised:

(1) Knowledge hubs for DRR science for the implementation of the Sendai Framework

(2) Science and technology for addressing gender inequality in disaster risk

(3) Supportive publishing practices in DRR: Leaving no scientist behind

(4) The role of youth in the application of science for DRR

(5) Bioethics and ethics of science and technology in DRR

(6) Research funding for DRR

Notable successes relating to these included the commitment to launch a Women in DRR Science platform supported by UN Women, the United Nations Office for Disaster Risk Reduction (UNISDR), and the United Nations Educational, Scientific, and Cultural Organization (UNESCO) over the coming few years; and the launch of the Young Scientists in DRR platform, which is coordinated by the UN Major Group for Children and Youth (UN MGCY).

\section{Call to Action}

The conference was successful in setting an agenda for the DRR science and policy-making communities for the implementation of the Sendai Framework. Scientists are invited to transfer knowledge, tools, and innovation to member states to reduce disaster risk.

UNISDR invited scientific, academia, and research institutions, organizations, networks, platforms, and other actors working on disaster risk reduction to join the Science and Technology Partnership. The work of the partnership and the UNISDR Scientific and Technical Advisory Group will be guided by the Road Map and the Sendai Framework. Progress made will be reported to the Global Platforms on Disaster Risk Reduction to be organized every two years as of 2017. The Road Map consists of proposals for concrete project work and research areas.

If you would like to highlight existing work or commit to making a new contribution to the Road Map delivery, please contact UNISDR by emailing unisdrstc@un.org. The outcomes of the Science and Technology Conference are available on the conference website. ${ }^{3}$ In addition, an article highlighting the scientific concepts and historic basis for the conference written by a core group of the organizing committee with Public Health England and UNISDR (Aitsi-Selmi 2016) is published in this edition of the International Journal of Disaster Risk Science.

Open Access This article is distributed under the terms of the Creative Commons Attribution 4.0 International License (http://crea tivecommons.org/licenses/by/4.0/), which permits unrestricted use, distribution, and reproduction in any medium, provided you give appropriate credit to the original author(s) and the source, provide a link to the Creative Commons license, and indicate if changes were made.

\section{References}

Aitsi-Selmi, A., V. Murray, C. Wannous, C. Dickinson, D. Johnston, A. Kawasaki, A.-S. Stevance, T. Yeung, et al. 2016. Reflections on a science and technology agenda for 21 st century disaster risk reduction. Based on the scientific content of the 2016 UNISDR Science and Technology Conference on the Implementation of the Sendai Framework for Disaster Risk Reduction 2015-2030. International Journal of Disaster Risk Science 7(1). doi:10.1007/ s13753-016-0081-x.

UNISDR (United Nations Office for Disaster Risk Reduction). 2015a. Sendai framework for disaster risk reduction 2015-2030. Geneva: UNISDR. http://www.unisdr.org/files/43291_sendaifra meworkfordrren.pdf. Accessed 10 Feb 2016.

UNISDR (United Nations Office for Disaster Risk Reduction). 2015b. UNISDR science and technology road map for the UNISDR Science and Technology Partnership supporting the implementation of Sendai Framework for Disaster Risk Reduction 2015-2030. http://www.preventionweb.net/files/45270_unisdrscien ceandtechnologyroadmap.pdf. Accessed 10 Feb 2016.

\footnotetext{
${ }^{3}$ http://www.preventionweb.net/files/45270_unisdrscienceandtechno logyconferenc[2].pdf.
} 